\title{
INTERDEPENDÊNCIA NA ABSORÇÃO E REDISTRIBUIÇÃO DE FÓSFORO ENTRE PLANTA MÃE E FILHA DE BANANEIRA ${ }^{1}$
}

\author{
AUGUSTO TIBURCIO CAVALCANTE², EVERARDO VALADARES DE SÁ BARRETTO SAMPAIO³, \\ UIDED MAAZE TIBURCIO CAVALCANTE ${ }^{2}$
}

\begin{abstract}
RESUMO - Apesar da importância do conhecimento da interdependência entre planta mãe e filha da bananeira, para adoção de manejos adequados, pouco tem sido pesquisado no Brasil. Foi montado um experimento, medindo a redistribuição de ${ }^{32} \mathrm{P}$ entre mãe e filha, cultivadas por $2 ; 4$ e 6 meses, adubadas ou não com P, aplicando-se ${ }^{32} \mathrm{P}$ no solo. As plantas cresceram até a última colheita, com mais massa na mãe (1450 g) que na filha (900 g), sem resposta à adubação. Os rizomas tinham as maiores biomassas (53-68\%) a as velas as menores (2-4\%), enquanto o inverso ocorreu com os teores de $\mathrm{P}\left(1,4-2,6\right.$ e 3,3-5,4 $\left.\mathrm{mg} \mathrm{kg}^{-1}\right)$. Em todas as épocas, houve redistribuição da mãe para a filha e vice-versa, mas a mãe reteve a maior proporção do ${ }^{32} \mathrm{P}$, embora declinante (95 a 78\%), enquanto a filha dividiu igualmente com a mãe, até os seis meses, quando reteve uma proporção maior (60\%). Mais ${ }^{32} \mathrm{P}$ dirigiu-se para os rizomas e pseudocaules, e menos para as velas, com folhas e raízes em posições intermediárias, mas as concentrações por unidade de massa ou de $\mathrm{P}$ total foram maiores nas velas. Portanto, mãe e filha mantiveram-se interdependentes, com ampla distribuição do ${ }^{32} \mathrm{P}$ absorvido, embora com preferência para as velas.
\end{abstract}

Termos para indexação: adubação, atividade específica, folhas, rizoma, translocação, velas.

\section{INTERDEPENDENCE BETWEEN MOTHER AND DAUGHTER BANANA PLANTS IN THEIR ABSORPTION AND REDISTRIBUTION OF PHOSPHORUS}

\begin{abstract}
Although knowledge of the interdependence between banana mother and daughter plants is important to establish adequate management practices, the subject has been little studied in Brazil. An experiment was set up to measure ${ }^{32} \mathrm{P}$ redistribution between mother and daughter plants, grown for 2, 4 and 6 months, with and without $\mathrm{P}$ fertilization, applying ${ }^{32} \mathrm{P}$ in the soil. Masses increased until the last harvest, being higher in mothers ( $1450 \mathrm{~g})$ than in daughters $(900 \mathrm{~g})$, without fertilizer effect. Rhizomes had the highest plant biomasses (53-68\%) and corm the lowest ones (2-4\%), while the opposite occurred with P rates (0.14-0.26 e $0.33-0.54 \%)$. At all harvests, there were redistribution between mothers and daughters, and vice versa, but while mothers retained most of their P, although declining with time (95 to $78 \%$ ); daughters divided their P equally with their mothers, except at the last harvest when they retained more $(60 \%)$. More ${ }^{32} \mathrm{P}$ was translated to rhizomes and pseudo stems and less to corms, with leaves and roots at intermediate positions. However, ${ }^{32} \mathrm{P}$ concentrations per mass or total $\mathrm{P}$ units were higher in the corms. Therefore, mothers and daughters remained interdependent, with ample distribution of the absorbed ${ }^{32} \mathrm{P}$, although with preference for the corms.
\end{abstract}

Index terms: corm, fertilization, leaves, rhizomes, specific activity, redistribution.

\section{INTRODUÇÃo}

A produção anual de banana no Brasil, em 2003, foi de mais de 6,8 milhões de toneladas (SIDRA/IBGE, 2005). O Nordeste contribuiu com 2,2 milhões de toneladas, colhidos em 176 mil ha, e Pernambuco, com 418 mil toneladas, em 35 mil ha, com predominância da cultivar Pacovan. Esta cultivar é um mutante natural da Prata, ocorrido no Ceará e introduzido em Pernambuco por volta de 1976 que, por ser mais produtiva, vem ocupando o lugar desta.

A bananeira necessita de solos férteis para um bom desenvolvimento, e a produção continuada exige adubação, para reposição dos nutrientes exportados com a colheita (Raghupathi et al., 2002). A adubação da bananeira é prática corrente, considerando que a nutrição é fator de produção de importância devido à alta quantidade de biomassa produzida em curto espaço de tempo (Lopez \& Espinosa, 1995, 1998) e para que alcance maior produtividade (Martin-Prével, 1980). Atualmente, os fertilizantes constituem um dos principais componentes do custo de produção da cultura (Maia et al., 2003). Entre os nutrientes mais carentes nos bananais, está o fósforo, geralmente presente nos solos brasileiros em concentrações baixas e com alta proporção em formas químicas pouco disponíveis às plantas (Novais \& Smyth, 1999).

A otimização da adubação requer o conhecimento detalhado da distribuição de nutrientes dentro das plantas. Na bananeira, esta distribuição tem uma complexidade maior que em outras culturas por seu modo de crescimento e de propagação (Kurien et al., 2000). As plantas crescem a partir do rizoma, que desenvolve gemas laterais, que dão origem ao sistema aéreo composto de bainhas foliares agrupadas em pseudocaule, terminando nas lâminas foliares (para as quais se reserva a denominação de folhas) e envolvendo o meristema apical (denominado de vela), que eventualmente emite uma única inflorescência e morre. A continuidade da planta (planta-mãe) se dá pelo progressivo desenvolvimento de novas gemas que vão formando plantas-filhas, agrupadas em touceiras. As cultivares comerciais, como a Pacovan, não produzem sementes viáveis, e a propagação é vegetativa, transplantando-se mudas (plantas-filhas), já com seu próprio rizoma.

No início de seu desenvolvimento, as plantas-filhas dependem dos nutrientes supridos pela planta-mãe. Com seu crescimento, tendem a ficar independentes, mas enquanto formam um agrupamento de plantas interligadas, mães e filhas podem manter alguma interdependência, trocando nutrientes. Este assunto tem sido pouco estudado e nenhum trabalho foi encontrado com a cultivar Pacovan. Para suprir esta lacuna, foi montado experimento utilizando ${ }^{32} \mathrm{P}$ como traçador e uma técnica de colocação das mudas em sacos, a qual permitiu o desenvolvimento de plantas mães e filhas de forma que seus sistemas radiculares cresceram isoladamente.

\section{MATERIAL E MÉTODOS}

Em plantio comercial, foram escolhidas mudas da cultivar Pacovan (Musa AAB), subgrupo Prata, que apresentavam brotação lateral em fase inicial de crescimento. Elas foram transplantadas para sacos de polietileno, contendo 47,5 kg de solo Podzólico VermelhoAmarelo Tb Distrófico A fraco, textura arenosa/média. O saco tinha um orifício coincidente com o orifício de outro saco, colocado a seu lado, formando um par, com a mesma quantidade do mesmo solo. As mudas foram colocadas de modo que sua brotação lateral fosse introduzida no

\footnotetext{
${ }^{1}$ (Trabalho 004/2005). Recebido: 05/01/2005. Aceito para publicação: 09/06/2005

2 Empresa Pernambucana de Pesquisa Agropecuária - IPA. Av. Gal. San Martin 1371, CEP 50630-060, Recife-PE, augustotiburcio@yahoo.com.br.

${ }^{32}$ Universidade Federal de Pernambuco. Av. Prof. Luís Freire, 1000, CEP 50670-420, Recife-PE, Departamento de Energia Nuclear, esampaio@ufpe.br; Departamento de Micologia, umaaze@yahoo.com.br.

Autor para correspondência: Augusto Tiburcio Cavalcante
} 
saco vizinho, através dos orifícios justapostos, e ajustada perfeitamente com uma liga de borracha. Desta forma, as raízes da planta-mãe e as da planta-filha cresceram em sacos distintos.

O experimento foi conduzido a céu aberto, na sede da Empresa Pernambucana de Pesquisa Agropecuária (IPA), em Recife-PE. As mínimas e máximas de temperatura, umidade relativa do ar e precipitação pluviométrica do período foram, respectivamente, $25,2^{\circ} \mathrm{C}, 56 \%$ e $50,4 \mathrm{~mm}$ e $26,7^{\circ} \mathrm{C}, 85 \%$ e $475,8 \mathrm{~mm}$ (Instituto Nacional de Meteorologia - INEMET).

Amostras das mudas e do solo foram analisadas na IPA. Os tecidos das mudas tinham, na matéria seca $\left(\mathrm{g} \mathrm{kg}^{-1}\right)$ : pseudocaule $-7,0$ de N; 1,6 de P; 85,8 de K; 5,6 de Ca, e 3,0 de Mg; rizoma-5,0 de N; 0,8 de $\mathrm{P} ; 34,3$ de $\mathrm{K} ; 2,8$ de Ca, e 3,0 de Mg; gema lateral-9,2 de N; 1,5 de P; 34,3 de K; 2,0 de Ca, e 1,6 de Mg. A análise do solo apresentou pH 5,0; $8 \mathrm{~g} \mathrm{~kg}^{-1} \mathrm{de} \mathrm{N} ; 47 \mathrm{~g} \mathrm{~kg}^{-1}$ de C; e $1 \mathrm{mg}$ de P, $11 \mathrm{mg} \mathrm{de} \mathrm{K}, 0,5 \mathrm{cmol}_{\mathrm{c}} \mathrm{de} \mathrm{Al}^{+++}$ e $0,2 \mathrm{cmol}$ de $\mathrm{Ca}^{++}+\mathrm{Mg}^{++}$, por $\mathrm{dm}^{3}$ de solo. Com base nestas análises, foram realizadas adubação orgânica $\left(7,5 \mathrm{tha}^{-1}\right.$ de esterco de curral, com 9,0 $\mathrm{g} \mathrm{kg}^{-1}$ de $\mathrm{N} ; 3,8 \mathrm{~g} \mathrm{~kg}^{-1}$ de P; 23,9 $\mathrm{g} \mathrm{kg}^{-1}$ de $\mathrm{K} ; 12,8 \mathrm{~g} \mathrm{~kg}^{-1}$ de Ca, e 3,8 $\left.\mathrm{g} \mathrm{kg}^{-1} \mathrm{de} \mathrm{Mg}\right)$ e calagem $\left(2,7 \mathrm{tha}^{-1}\right.$ de calcário dolomítico com PRNT de $73,64 \%$ ). Após 26 dias da mistura do corretivo e da matéria orgânica com o solo, foi realizada nova análise no solo (pH 6,8;30mg de $\mathrm{P} ; 150 \mathrm{mg}$ de $\mathrm{K}$; $0,0 \mathrm{cmol}_{\mathrm{c}} \mathrm{de}^{\mathrm{Al}}{ }^{++}$; e 1,9 $\mathrm{cmol}_{\mathrm{c}}$ de $\mathrm{Ca}^{++}+\mathrm{Mg}^{++}$por $\mathrm{dm}^{3}$ de solo) e, a partir dela, o solo foi adubado com 5,7 $\mathrm{g}$ de $\mathrm{N} \mathrm{e} \mathrm{11,4} \mathrm{g}$ de $\mathrm{K}_{2} \mathrm{O}$ por saco.

$\mathrm{O}$ experimentou constou de 12 tratamentos, com 4 repetições, em delineamento de blocos ao acaso, com esquema fatorial de $2 \times 2 \times 3$, correspondendo os fatores à ausência ou presença de adubação fosfatada ( 0 e 9,93 g de P por saco), aplicação do ${ }^{32} \mathrm{P}$ no solo da plantamãe ou no solo da planta-filha e três períodos de desenvolvimento da planta-filha, a partir de seu surgimento na superfície do solo $(2 ; 4$ e 6 meses). O plantio de todos os tratamentos foi feito no mesmo dia. Durante a condução, foi efetuada irrigação sempre que necessário, mantendo-se a umidade dentro da capacidade de campo. Ao fim dos períodos de desenvolvimento descritos acima, foi aplicado o ${ }^{32} \mathrm{P}$, junto com a água de rega. $\mathrm{O}$ traçador $\left(1 \mathrm{~mL}\right.$ de $\mathrm{Na}_{2} \mathrm{H}^{32} \mathrm{PO}_{4}$, atividade de 555 $\mathrm{MBq}$ ) foi adquirido do Instituto de Pesquisas Energéticas e Nucleares da Comissão Nacional de Energia Nuclear de São Paulo (IPEN-CNEN/ $\mathrm{SP})$.

As coletas, de solo e planta, foram realizadas sete dias após a aplicação do ${ }^{32} \mathrm{P}$, sendo as plantas divididas em folha, vela, pseudocaule, rizoma e raiz. O solo foi analisado quanto ao fósforo, utilizando-se do extrator de Mehlich-1 e as partes vegetais após digestão nítrico perclórica, por colorimetria pelo método do molibdato - ácido ascórbico (EMBRAPA, 1999). O ${ }^{32} \mathrm{P}$ foi determinado por cintilação líquida, através da radiação Cerenkov, fazendo-se as correções da radiatividade natural (background), da eficiência de contagem e do decaimento radiativo.

Os dados foram analisados estatisticamente através de análise de variância, e as médias comparadas pelo teste de Tukey, a 5\% de probabilidade, usando-se o programa Statistica (Statsoft 1995). Os dados das variáveis, expressos em percentagem, foram transformados em arcoseno. As análises iniciais foram feitas considerando os fatores: ausência ou presença de adubação fosfatada; aplicação do ${ }^{32} \mathrm{P}$ no solo da plantamãe ou no solo da planta-filha; os três períodos de desenvolvimento (2; 4 e 6 meses); a planta-mãe e a planta-filha; e as cinco partes da planta (folha, vela, pseudocaule, rizoma e raiz). Para a maioria das variáveis analisadas, algum dos fatores não teve efeito significativo (às vezes não era esperado que tivesse) e as médias de seus tratamentos não são mostradas. Nestes casos, as comparações dos outros fatores foram feitas considerando as médias dos tratamentos do fator nãosignificativo. Por exemplo, na comparação das massas das plantas, em qualquer das épocas, o fator aplicação do ${ }^{32} \mathrm{P}$ não deveria e não teve influência e, portanto, foi desconsiderado. Por esta razão e pelo elevado número de possíveis comparações, apenas as que foram consideradas mais importantes, foram expressas por grupos de letras nas tabelas. $\mathrm{Na}$ seção de resultados, a parte de cada variável descreve que fatores foram considerados e, em alguns poucos casos, refere-se a diferenças entre tratamentos que não estão discriminadas por letras nas tabelas.

\section{RESULTADOS E DISCUSSÃO}

\section{Massa seca e teor de $P$ nas plantas}

Após o transplantio das mudas, elas continuaram a crescer, aumentando de massa até a última data de colheita (Tabela 1). As plantasmães, que foram plantadas com pouco mais de $700 \mathrm{~g}$, aumentaram cerca de $100 \mathrm{~g}$, até os dois meses após a emergência das plantas-filhas, e depois cerca de $300 \mathrm{~g}$ a cada dois meses, atingindo $1.450 \mathrm{~g}$, aos seis meses. $\mathrm{O}$ crescimento mais baixo, no primeiro período, pode ter sido um reflexo do estresse causado pelo transplante. As plantas-filhas, nos primeiros quatro meses, tiveram um crescimento mais lento que as mães, com um aumento de massa de $250 \mathrm{~g}$, até os dois meses e também dos dois aos quatro meses. No último período, o aumento subiu para mais de $400 \mathrm{~g}$, indicando que elas estavam entrando na fase de crescimento exponencial. Apesar deste impulso no crescimento, aos seis meses, as plantas-filhas (900 g) ainda tinham menor massa que as mães.

TABELA 1 - Massa seca (g) das plantas mãe e filha, 2; 4 e 6 meses após a emergência da planta-filha. Médias dos tratamentos adubados e não-adubados e com aplicação de ${ }^{32} \mathrm{P}$ na planta-mãe e na planta-filha.

\begin{tabular}{lccr}
\hline \multicolumn{1}{c}{ Parte da planta } & \multicolumn{3}{c}{ Época (meses) } \\
\cline { 2 - 4 } & 2 & \multicolumn{1}{c}{ Planta-mãe } \\
\hline Folha & $30 \mathrm{C}^{1}$ & $40 \mathrm{C}$ & $60 \mathrm{C}$ \\
Vela & $15 \mathrm{C}$ & $20 \mathrm{C}$ & $30 \mathrm{C}$ \\
Pseudocaule & $240 \mathrm{~B}$ & $260 \mathrm{~B}$ & $310 \mathrm{~B}$ \\
Rizoma & $510 \mathrm{~A}$ & $720 \mathrm{~A}$ & $980 \mathrm{~A}$ \\
Raiz & $20 \mathrm{C}$ & $50 \mathrm{C}$ & $70 \mathrm{C}$ \\
Total & $815 \mathrm{a}^{2}$ & $1090 \mathrm{a}$ & $1450 \mathrm{a}$ \\
& & Planta-filha & \\
Folha & $20 \mathrm{C}$ & $30 \mathrm{CD}$ & $50 \mathrm{D}$ \\
Vela & $10 \mathrm{C}$ & $15 \mathrm{C}$ & $30 \mathrm{D}$ \\
Pseudocaule & $60 \mathrm{~B}$ & $110 \mathrm{~B}$ & $240 \mathrm{~B}$ \\
Rizoma & $140 \mathrm{~A}$ & $260 \mathrm{~A}$ & $480 \mathrm{~A}$ \\
Raiz & $20 \mathrm{C}$ & $60 \mathrm{C}$ & $110 \mathrm{C}$ \\
Total & $250 \mathrm{~b}$ & $475 \mathrm{~b}$ & $910 \mathrm{~b}$ \\
\hline
\end{tabular}

${ }^{1}$ Médias na mesma coluna, para planta-mãe ou planta-filha, seguidas de mesma letra maiúscula não diferem significativamente, pelo teste de Tukey, a $5 \%$ de probabilidade.

${ }^{2}$ Médias na mesma coluna, seguidas de mesma letra minúscula, não diferem significativamente, pelo teste de Tukey, a $5 \%$ de probabilidade.

Não houve diferenças significativas entre plantas adubadas e não-adubadas com fósforo. Por isto, só as médias foram mostradas na Tabela 1. A causa mais provável é que mesmo o tratamento não-adubado tinha boa disponibilidade de nutrientes, supridos pela fertilização geral com adubo orgânico. O solo das plantas não-adubadas tinha, em média, $66 \mathrm{mg} \mathrm{dm}^{-3} \mathrm{de}$ P, enquanto o adubado tinha $102 \mathrm{mg} \mathrm{dm}^{-3}$ de P. São valores altos, na faixa que os solos têm amplo P disponível. Segundo Veerannah et al. (1976), valores de $26 \mathrm{mg} \mathrm{dm}^{-3}$ de $\mathrm{P}$ já são adequados para a cultura da bananeira. Ausência de resposta a doses de fósforo acima de $25 \mathrm{~g}$ por touceira tem sido reportada em outros trabalhos que adicionaram esterco antes do plantio (Maia et al., 2003).

Também não houve diferenças de massa entre plantas que receberam ${ }^{32} \mathrm{P}$ no solo da planta-mãe ou da planta-filha e, por isso, só as médias foram apresentadas na Tabela 1. Isso já era esperado porque $o$ ${ }^{32} \mathrm{P}$ foi usado como marcador, sem carregador, isto é, com uma concentração muito baixa de $\mathrm{P}$, composta apenas dos átomos do isótopo radiativo necessário para acompanhar sua movimentação na planta e, portanto, adicionando uma quantidade muito pequena de $\mathrm{P}$ ao solo. No entanto, o registro é importante porque a ausência de diferenças assegura que os pares de plantas em que foram feitas as marcações cruzadas, eram relativamente uniformes e que as comparações entre marcação de mãe, em uma unidade experimental, e de filha, em outra, podem ser estudadas em confronto. 
Em todas as plantas, tanto mães quanto filhas, as maiores proporções das massas totais (Tabela 1) estavam nos rizomas (53 a $68 \%$ ), seguidos dos pseudocaules (21 a $29 \%$ ), enquanto as menores estavam nas velas (2 a 4\%). Folhas e raízes tiveram proporções de massa pouco acima destas últimas, em geral, sem diferenças estatísticas significativas. Ordenações semelhantes nas proporções foram encontradas por Twyford \& Walmsley (1973), trabalhando com bananeira 'Robusta', e por Buragohain \& Shanmugavelu (1986), com a bananeira 'Vayal Vazhai'.

Se a adubação fosfatada não teve efeito na produção de massa, resultou em aumentos nos teores de $\mathrm{P}$ das diferentes partes das plantas, aos dois meses após a emergência das plantas-filhas (Tabela 2). Nos períodos seguintes, muitas das diferenças não foram estatisticamente significativas. Também aos dois meses, os teores foram mais altos nas plantas-filhas que nas mães, não havendo muitas diferenças significativas nos períodos seguintes. Os teores de algumas das partes foram maiores aos dois meses que nos períodos seguintes. Portanto, as concentrações de $\mathrm{P}$ nas plantas não parecem ter sido limitantes ao crescimento, mas houve algum acúmulo nos tecidos, em resposta à maior disponibilidade de $\mathrm{P}$ no solo.

TABELA 2 - Teor de fósforo $\left(\mathrm{g} \mathrm{kg}^{-1}\right)$ nas partes da planta-mãe e da planta-filha, 2; 4 e 6 meses após a emergência da plantafilha, cultivadas em solo não-adubado e adubado com fósforo.

\begin{tabular}{cccc}
\hline Parte da planta & \multicolumn{3}{c}{ Época (meses) } \\
\cline { 2 - 4 } Solo adubado, planta-mãe \\
Folha & $2,8 \mathrm{aB} 2^{1}$ & $1,9 \mathrm{aA} 3$ & $1,7 \mathrm{aB} 3$ \\
Vela & $4,5 \mathrm{aB} 1$ & $3,4 \mathrm{aA} 1$ & $4,1 \mathrm{bB} 1$ \\
Pseudocaule & $1,6 \mathrm{aB} 4$ & $2,7 \mathrm{aA} 2$ & $2,5 \mathrm{aB} 2$ \\
Rizoma & $2,0 \mathrm{aB} 3$ & $2,1 \mathrm{aA} 3$ & $1,4 \mathrm{aA} 3$ \\
Raiz & $2,6 \mathrm{aA} 2$ & $2,2 \mathrm{aA} 3$ & $1,6 \mathrm{bB} 3$ \\
& \multicolumn{2}{c}{ Solo adubado, planta-filha } \\
Folha & $3,2 \mathrm{aA} 2$ & $2,0 \mathrm{aA} 3$ & $2,2 \mathrm{aA} 3$ \\
Vela & $5,4 \mathrm{aA} 1$ & $3,5 \mathrm{aA} 1$ & $5,4 \mathrm{aA} 1$ \\
Pseudocaule & $3,1 \mathrm{aA} 2$ & $2,8 \mathrm{aA} 2$ & $3,1 \mathrm{aA} 2$ \\
Rizoma & $2,6 \mathrm{aA} 3$ & $1,4 \mathrm{aA} 4$ & $1,4 \mathrm{aA} 4$ \\
Raiz & $2,9 \mathrm{aA} 23$ & $2,3 \mathrm{aA} 3$ & $2,6 \mathrm{aA} 3$ \\
& Solo não-adubado, planta-mãe \\
Folha & $2,4 \mathrm{bB} 2$ & $1,4 \mathrm{bB} 2$ & $1,9 \mathrm{aA} 4$ \\
Vela & $3,9 \mathrm{bB} 1$ & $3,3 \mathrm{aB} 1$ & $4,7 \mathrm{aA} 1$ \\
Pseudocaule & $0,9 \mathrm{bB} 4$ & $3,1 \mathrm{aA} 1$ & $2,7 \mathrm{aA} 2$ \\
Rizoma & $1,6 \mathrm{bB} 3$ & $1,5 \mathrm{bA} 2$ & $1,7 \mathrm{aA} 4$ \\
Raiz & $2,2 \mathrm{bB} 2$ & $1,6 \mathrm{bB} 2$ & $2,0 \mathrm{aA} 3$ \\
& Solo não-adubado, plantafilha \\
Folha & $3,1 \mathrm{aB} 2$ & $1,8 \mathrm{aA} 2$ & $2,1 \mathrm{aA} 3$ \\
Vela & $4,5 \mathrm{bA} 1$ & $3,7 \mathrm{aA} 1$ & $4,1 \mathrm{bB} 1$ \\
Pseudocaule & $2,5 \mathrm{bA} 3$ & $2,2 \mathrm{bB} 2$ & $3,0 \mathrm{aA} 2$ \\
Rizoma & $2,2 \mathrm{bA} 3$ & $1,8 \mathrm{aA} 2$ & $1,6 \mathrm{aA} 4$ \\
Raiz & $2,6 \mathrm{aA} 3$ & $2,0 \mathrm{aA} 2$ & $2,3 \mathrm{aA} 3$ \\
\hline
\end{tabular}

${ }^{1}$ Médias na mesma coluna, para a mesma parte da planta, comparando entre planta-mãe adubada e não-adubada ou entre planta-filha, adubada e nãoadubada, seguidas de mesma letra minúscula não diferem significativamente, pelo teste de Tukey, a 5\% de probabilidade.

${ }^{2}$ As letras maiúsculas referem-se às comparações entre planta-mãe e plantafilha, para a mesma parte da planta, o mesmo tratamento de adubação e a mesma época. Os dígitos depois das letras referem-se às comparações entre partes da planta, na mesma coluna, mesma adubação e mesmo tipo de planta.

As velas tiveram sempre os maiores teores de $\mathrm{P}(3,3$ a $5,4 \mathrm{~g} \mathrm{~kg}$ ${ }^{1}$ ), o que pode ser explicado por serem constituídas de tecidos meristemáticos, de intenso metabolismo, no qual o $\mathrm{P}$ tem um papel importante nas reações energéticas. Os menores teores, nas plantasfilhas, em geral, em todas as épocas, foram os dos rizomas $(1,4$ a 2,6 g $\left.\mathrm{kg}^{-1}\right)$. Já os menores teores nas plantas-mães ora foram os dos pseudocaules ( 2 meses, 0,9 a 1,6 $\mathrm{g} \mathrm{kg}^{-1}$ ), ora os das folhas (4 meses, 1,4 a 1,9 $\left.\mathrm{g} \mathrm{kg}^{-1}\right)$, ora os dos rizomas ( 6 meses, 1,4 a 1,7 $\left.\mathrm{g} \mathrm{kg}^{-1}\right)$, mas todos em faixas muito aproximadas e às vezes sem diferenças significativas. Balakrishnan \& Shanmugavelu (1985) detectaram comportamento semelhante em oito cultivares, de diferentes níveis de ploidia. Trabalhando com a cultivar Vayal Vazhai, Buragohain \& Shanmugavelu (1986) também observaram teor mais alto de fósforo no estádio inicial de crescimento, decrescendo no estádio de rebento, voltando a crescer até o estádio de florescimento e, a partir daí, novamente decrescendo na colheita. A faixa de variação dos teores nas folhas foi a mesma relatada por Fontes et al. (2003), em sua revisão de vários trabalhos.

Os conteúdos de $\mathrm{P}$ nas partes das plantas foram mais influenciados pelas suas massas que pelos teores do elemento (dados não mostrados, mas que podem ser calculados a partir das Tabelas $1 \mathrm{e}$ 2). Assim, os maiores conteúdos, em todas as plantas, estavam nos rizomas, seguidos dos pseudocaules. Folhas e velas tinham os menores conteúdos, semelhantes aos das raízes nas plantas-mães, mas, por vezes, inferiores nas plantas-filhas. Os conteúdos aumentaram com o tempo de crescimento, evidenciando a maior influência das massas crescentes que dos teores declinantes. Nas plantas-mães, os conteúdos dobraram, entre os dois (1,2 a 1,6 g de P) e os seis meses (2,5 a 2,9 mg), enquanto nas plantas-filhas triplicaram (de 0,6-0,7 g a 2,0 g), mas ainda ficaram abaixo dos conteúdos das mães. Não houve diferenças significativas entre plantas que receberam, ou não, fertilização fosfatada.

\section{Fósforo marcado na planta e no solo}

Em todas as épocas e na presença ou ausência de adubação prévia, houve sempre translocação do ${ }^{32} \mathrm{P}$ aplicado no solo da plantamãe para os órgãos da planta-filha e do solo da planta-filha para os da planta-mãe (Tabela 3). Portanto, as plantas mantiveram-se interdependentes até o final do experimento, uma característica que permite que uma se beneficie da absorção do sistema radicular da outra. Resultados semelhantes foram relatados por Balakrishnan \& Shanmugavelu (1985) e por Twyford (1967), tendo este estudado apenas a translocação no sentido da planta-mãe para a planta-filha. Outros trabalhos têm constatado interdependência e também mostrado grande mobilidade de $\mathrm{P}$ entre partes das plantas mães e filhas. Walmsley \& Twyford (1968a), em plantio já estabelecido de bananeira 'Robusta', chegaram à conclusão de que houve translocação da planta-mãe para a planta-filha, em três situações: 1 ) quando injetaram o ${ }^{32} \mathrm{P}$ no pseudocaule da planta-mãe; 2) quando aplicaram o ${ }^{32} \mathrm{P}$ no topo da planta-mãe já colhida, e 3) quando o ${ }^{32} \mathrm{P}$ foi aplicado no solo a $2,1 \mathrm{~m}$ da base da touceira. Nesta última situação, as raízes da planta-mãe, após a colheita, devem ter absorvido o ${ }^{32} \mathrm{P}$ e translocado porque, com 2 meses de idade, as raízes da planta-filha não atingiriam esta profundidade (Walmsley \& Twyford,1968c e Beugnon \& Champion, 1966). Buragohain \& Shanmugavelu (1985), estudando a translocação dentro da planta com as cultivares Monthan e Poovan, concluíram que houve translocação para o cacho e primeira folha quando ${ }^{32} \mathrm{P}$ foi aplicado no eixo distal da ráquis masculina. Kurien et al. (2000) verificaram a translocação preferencial de ${ }^{32} \mathrm{P}$, aplicado no colmo da cultivar Mysore, para a inflorescência masculina que, sendo desbastada, melhorava a qualidade dos frutos. O cacho é considerado um dreno forte de nutrientes (Pereira et al., 2000).

Apesar da ampla movimentação de $\mathrm{P}$ entre as plantas, sua distribuição foi diferente quando aplicado na planta-mãe ou na filha e também ao longo dos períodos de crescimento (Tabela 3). A planta-mãe reteve sempre a maior proporção do $\mathrm{P}$ que absorveu, embora fosse declinante ao longo do tempo, passando de $95 \%$, aos dois meses, para $78 \%$, aos seis meses. Já a planta-filha dividiu quase igualmente com a planta-mãe o $\mathrm{P}$ absorvido, aos dois e aos quatro meses, e somente na última época reteve uma proporção maior $(60 \%)$. Estes padrões contrariam a noção de que a planta-filha, mais frágil e com menor sistema radicular, dependeria mais da planta-mãe. Ao contrário, a filha estaria contribuindo com o suprimento da mãe até uma fase adiantada de seu crescimento. A razão desta aparente inversão poderia ser o maior aumento em biomassa e em conteúdo de $\mathrm{P}$ da planta-mãe, em relação à filha, e o suprimento relativamente abundante desta. Assim, o P absorvido pelo conjunto das 
TABELA 3 - Proporções (\%) do P do fertilizante absorvido pelas plantas, quando aplicado no solo da planta-mãe ou da planta-filha, após 2; 4 e 6 meses da emergência da planta-filha.

\begin{tabular}{|c|c|c|c|c|c|c|}
\hline \multirow[t]{3}{*}{ Parte da planta } & \multicolumn{6}{|c|}{ Época (meses) } \\
\hline & \multicolumn{2}{|c|}{2} & \multicolumn{2}{|c|}{4} & \multicolumn{2}{|c|}{6} \\
\hline & Mãe & Filha & Mãe & Filha & Mãe & Filha \\
\hline & \multicolumn{6}{|c|}{$P$ aplicado na planta-mãe } \\
\hline Folha & $1,4 \mathrm{C}^{1}$ & $0,3 \mathrm{~A}$ & $7,4 \mathrm{C}$ & $1,0 \mathrm{~B}$ & $6,3 \mathrm{CD}$ & $2,7 \mathrm{~B}$ \\
\hline Vela & $0,7 \mathrm{C}$ & $0,3 \mathrm{~A}$ & $2,8 \mathrm{D}$ & $0,9 \mathrm{~B}$ & $1,3 \mathrm{D}$ & $0,5 \mathrm{~B}$ \\
\hline Pseudocaule & $12,0 \mathrm{~B}$ & $0,7 \mathrm{~A}$ & $14,8 \mathrm{~B}$ & $3,7 \mathrm{AB}$ & $24,2 \mathrm{~B}$ & $5,8 \mathrm{AB}$ \\
\hline Rizoma & $78,1 \mathrm{~A}$ & $3,1 \mathrm{~A}$ & $53,7 \mathrm{~A}$ & $7,4 \mathrm{~A}$ & $37,2 \mathrm{~A}$ & $9,4 \mathrm{~A}$ \\
\hline Raiz & $2,7 \mathrm{C}$ & $0,7 \mathrm{~A}$ & $6,5 \mathrm{CD}$ & $1,8 \mathrm{~B}$ & $9,4 \mathrm{C}$ & $3,2 \mathrm{~B}$ \\
\hline \multirow[t]{2}{*}{ Total } & $94,9 \mathrm{a}^{2}$ & $5,1 \mathrm{~b}$ & $85,2 \mathrm{a}$ & $14,8 \mathrm{~b}$ & $78,4 \mathrm{a}$ & $21,6 \mathrm{~b}$ \\
\hline & \multicolumn{6}{|c|}{$P$ aplicado na planta-filha } \\
\hline Folha & $2,7 \mathrm{C}$ & $2,9 \mathrm{C}$ & $2,5 \mathrm{C}$ & $3,7 \mathrm{C}$ & $3,5 \mathrm{~B}$ & $6,7 \mathrm{C}$ \\
\hline Vela & $1,4 \mathrm{C}$ & $2,7 \mathrm{C}$ & $1,2 \mathrm{C}$ & $1,2 \mathrm{C}$ & $0,5 \mathrm{~B}$ & $0,5 \mathrm{D}$ \\
\hline Pseudocaule & $11,0 \mathrm{~B}$ & $16,4 \mathrm{~B}$ & $14,8 \mathrm{~B}$ & $13,6 \mathrm{~B}$ & $15,9 \mathrm{~A}$ & $26,7 \mathrm{~A}$ \\
\hline Rizoma & $34,2 \mathrm{~A}$ & $21,9 \mathrm{~A}$ & $28,4 \mathrm{~A}$ & $28,4 \mathrm{~A}$ & $16,4 \mathrm{~A}$ & 14,4 B \\
\hline Raiz & $2,7 \mathrm{C}$ & $4,1 \mathrm{C}$ & $2,5 \mathrm{C}$ & $3,7 \mathrm{C}$ & $3,6 \mathrm{~B}$ & $11,8 \mathrm{~B}$ \\
\hline Total & $52,0 \mathrm{a}$ & $48,0 \mathrm{a}$ & $49,4 \mathrm{a}$ & $50,6 \mathrm{a}$ & $39,9 \mathrm{~b}$ & $60,1 \mathrm{a}$ \\
\hline
\end{tabular}

${ }^{1}$ Médias na mesma coluna, para planta-mãe ou planta-filha, seguidas de mesma letra maiúscula não diferem significativamente, pelo teste de Tukey, a $5 \%$ de probabilidade.

${ }^{2}$ Médias na mesma linha e no mesmo período, seguidas de mesma letra minúscula, não diferem significativamente, pelo teste de Tukey, a $5 \%$ de probabilidade.

duas poderia ser dirigido para onde houvesse maior demanda. Com o crescimento crescente da planta-filha, a proporção alocada a ela passou a aumentar. Deve-se levar em conta, também, que as plantas-mães ainda estavam em fase vegetativa de crescimento e estariam acumulando massa e P até o florescimento e a frutificação. A translocação poderia ter tido um padrão diverso caso fosse testada durante ou após esta fase final do ciclo das plantas-mães. Diferentes cultivares também poderiam ter outro padrão (Bapat et al., 2001).

A distribuição do ${ }^{32} \mathrm{P}$ entre as partes de cada planta (Tabela 3) foi muito mais influenciada pelas massas que pelas atividades específicas (Tabela 4). Assim, em quase todos os casos, o P absorvido dirigiu-se mais para os rizomas, seguidos dos pseudocaules, e menos para as velas, com folhas e raízes em posições intermediárias. Relato semelhante foi feito por Walmsley \& Twyford (1968b). Ao longo do tempo, as proporções para os rizomas foram decrescendo e as dos pseudocaules e raízes, aumentando.

Esta distribuição massal, comparando órgãos de tamanhos muito distintos, esconde preferências de acumulação relativa que só podem ser analisadas pelas atividades específicas. As proporções de ${ }^{32} \mathrm{P}$ em relação às massas $\mathrm{e}$ ao conteúdo de $\mathrm{P}$ das diferentes partes (Tabela 4) mostram que as velas foram um sítio de recepção preferencial do ${ }^{32} \mathrm{P}$, em quase todas as épocas e situações. Até os quatro meses, mais ${ }^{32} \mathrm{P}$ acumulou-se nas velas, por unidade de massa, que em qualquer outra parte. Aos seis meses, essa atividade específica por massa inverteu-se, com os menores valores nas velas. No entanto, as atividades específicas por unidade de $\mathrm{P}$ mantiveram-se as mais altas. Isso indica que as velas são sítios de metabolismo ativo, com rápida reciclagem de $\mathrm{P}$, o que parece confirmado pelos seus altos teores de $\mathrm{P}$ total (Tabela 2). Tal observação leva a crer ser a vela a parte da planta mais indicada para servir de amostragem na detecção da entrada de fósforo radiativo na bananeira, na fase vegetativa de crescimento. Esses resultados estão de acordo com os de Marchal \& Mallessard (1979) e Walmsley \& Twyford (1968b).

As diferenças em atividades específicas entre outras partes não parecem ter tido um padrão muito definido e, muitas vezes, foram pequenas, sugerindo que não havia movimentação preferencial de $\mathrm{P}$ para elas. Essa boa distribuição indica que ${ }^{32} \mathrm{P}$ foi livremente permutável com o fósforo dentro da planta. Resultados semelhantes foram encontrados por Walmsley \& Twyford (1968b), estudando a absorção e a translocação do ${ }^{32} \mathrm{P}$ da planta-mãe para a planta-filha com bananeira 'Robusta', em Trinidad. Eles admitiram que o ${ }^{32} \mathrm{P}$ eventualmente se torna distribuído por um simples processo de diluição.

TABELA 4 - Atividades específicas (contagens por minuto, $\mathrm{cpm}$ ) do ${ }^{32} \mathrm{P}$ do fertilizante, na matéria seca (MS, $\left.\mathrm{cpm} \mathrm{g}^{-1}\right)$ e no fósforo $\left(\mathrm{P}, \mathrm{cpm} \mathrm{mg}^{-1}\right)$, em diferentes partes das plantas, quando aplicado no solo da planta-mãe ou da planta-filha, após 2; 4 e 6 meses da emergência da planta-filha. Parte da planta Época (meses)

\begin{tabular}{|c|c|c|c|c|c|c|c|c|c|c|c|c|}
\hline \multirow[t]{4}{*}{ Parte da planta } & \multicolumn{12}{|c|}{ Época (meses) } \\
\hline & \multicolumn{4}{|c|}{2} & \multicolumn{4}{|c|}{4} & \multicolumn{4}{|c|}{6} \\
\hline & \multicolumn{2}{|c|}{ Mãe } & \multicolumn{2}{|c|}{ Filha } & \multicolumn{2}{|c|}{ Mãe } & \multicolumn{2}{|c|}{ Filha } & \multicolumn{2}{|c|}{ Mãe } & \multicolumn{2}{|c|}{ Filha } \\
\hline & MS & $\mathrm{P}$ & MS & $\mathrm{P}$ & $\mathrm{MS}$ & $\mathrm{P}$ & MS & $\mathrm{P}$ & $\mathrm{MS}$ & $\mathrm{P}$ & MS & $\mathrm{P}$ \\
\hline & \multicolumn{12}{|c|}{$P$ aplicado na planta-mãe } \\
\hline Folha & $21 c^{1}$ & $9 \mathrm{~b}$ & $8 \mathrm{~b}$ & $3 a$ & $18 \mathrm{~b}$ & $13 \mathrm{a}$ & $5 \mathrm{a}$ & $3 \mathrm{a}$ & $31 \mathrm{a}$ & $17 \mathrm{a}$ & $10 \mathrm{a}$ & $8 \mathrm{a}$ \\
\hline Vela & $59 \mathrm{a}$ & $17 \mathrm{a}$ & $16 \mathrm{a}$ & $5 \mathrm{a}$ & $27 \mathrm{a}$ & $13 \mathrm{a}$ & $7 \mathrm{a}$ & $2 \mathrm{a}$ & $4 \mathrm{~b}$ & $20 \mathrm{a}$ & $3 \mathrm{~b}$ & $11 \mathrm{a}$ \\
\hline Pseudocaule & $17 \mathrm{c}$ & $14 \mathrm{ab}$ & $8 \mathrm{~b}$ & $3 a$ & $12 \mathrm{~b}$ & $3 \mathrm{~b}$ & $6 a$ & $2 \mathrm{a}$ & $26 \mathrm{a}$ & $11 \mathrm{~b}$ & $7 \mathrm{ab}$ & $2 \mathrm{~b}$ \\
\hline Rizoma & $30 \mathrm{~b}$ & $17 \mathrm{a}$ & $7 \mathrm{~b}$ & $4 \mathrm{a}$ & $13 \mathrm{~b}$ & $9 \mathrm{a}$ & $7 \mathrm{a}$ & $3 \mathrm{a}$ & $10 \mathrm{~b}$ & $9 \mathrm{~b}$ & $5 \mathrm{ab}$ & $3 \mathrm{~b}$ \\
\hline \multirow[t]{2}{*}{ Raiz } & $20 \mathrm{c}$ & $13 \mathrm{ab}$ & $4 \mathrm{~b}$ & $3 a$ & $14 \mathrm{~b}$ & $9 a$ & $6 a$ & $3 \mathrm{a}$ & $31 \mathrm{a}$ & $18 \mathrm{a}$ & $7 \mathrm{ab}$ & $3 \mathrm{~b}$ \\
\hline & \multicolumn{12}{|c|}{$P$ aplicado na planta-filha } \\
\hline Folha & $6 \mathrm{~b}$ & $3 a$ & $37 \mathrm{~b}$ & $13 \mathrm{bc}$ & $5 \mathrm{a}$ & $3 \mathrm{a}$ & $21 \mathrm{~b}$ & $13 \mathrm{a}$ & $10 \mathrm{a}$ & $11 \mathrm{a}$ & $30 \mathrm{a}$ & $16 \mathrm{~b}$ \\
\hline Vela & $19 \mathrm{a}$ & $6 a$ & $49 \mathrm{a}$ & $9 \mathrm{~cd}$ & $7 \mathrm{a}$ & $3 \mathrm{a}$ & $28 \mathrm{a}$ & $9 \mathrm{ab}$ & $4 \mathrm{a}$ & $8 \mathrm{ab}$ & $6 \mathrm{~b}$ & $22 \mathrm{a}$ \\
\hline Pseudocaule & $5 \mathrm{~b}$ & $3 \mathrm{a}$ & $33 \mathrm{~b}$ & $15 \mathrm{ab}$ & $6 a$ & $3 a$ & $15 \mathrm{bc}$ & $7 \mathrm{~b}$ & $9 \mathrm{a}$ & $3 \mathrm{~b}$ & $30 \mathrm{a}$ & $11 \mathrm{bc}$ \\
\hline Rizoma & $7 \mathrm{~b}$ & $4 \mathrm{a}$ & $14 \mathrm{c}$ & $6 \mathrm{~d}$ & $6 \mathrm{a}$ & $4 \mathrm{a}$ & $13 \mathrm{c}$ & $8 \mathrm{ab}$ & $5 \mathrm{a}$ & $3 \mathrm{~b}$ & $11 \mathrm{~b}$ & $8 \mathrm{c}$ \\
\hline Raiz & $5 \mathrm{~b}$ & $3 \mathrm{a}$ & $33 \mathrm{~b}$ & $19 \mathrm{a}$ & $6 \mathrm{a}$ & $3 \mathrm{a}$ & $15 \mathrm{bc}$ & $7 \mathrm{~b}$ & $8 \mathrm{a}$ & $6 \mathrm{ab}$ & $27 \mathrm{a}$ & $13 \mathrm{bc}$ \\
\hline
\end{tabular}

${ }^{1}$ Médias na mesma coluna, para planta-mãe ou planta-filha, seguidas de mesma letra não diferem significativamente, pelo teste de Tukey, a $5 \%$ de probabilidade. 
A análise das atividades específicas também mostra, em todos os casos, maiores valores nas partes da planta em cujo solo foi aplicado $\mathrm{o}^{32} \mathrm{P}$ que naquela que recebeu por translocação da outra. Essa forma de interpretação não modifica a que foi feita com base na distribuição do ${ }^{32} \mathrm{P}$ total (Tabela 3), exceto para os casos das aplicações nas plantasfilhas aos dois e quatro meses. Nesses casos, a distribuição aparentemente igualitária do ${ }^{32} \mathrm{P}$ entre planta-filha e planta-mãe recebeu um reforço da maior massa da planta-mãe. Quando esse reforço é descontado, calculando-se por unidade de massa, as plantas-filhas passam a ter preferência no acúmulo do $\mathrm{P}$ que elas mesmas absorveram.

Vale a pena registrar que foi encontrada radiatividade no solo das plantas que não receberam ${ }^{32} \mathrm{P}$, acima dos níveis naturais, mas de baixa magnitude (dados não mostrados). Ela pode ser proveniente de substâncias secretadas pelas raízes das plantas, da escamação dessas raízes ou mesmo de pequenos fragmentos de raízes deixados no solo quando de sua separação. Não foram encontrados, na literatura, trabalhos com bananeira que apresentassem resultados para o confronto sobre o assunto. Naturalmente, a radiatividade nos solos que receberam ${ }^{32} \mathrm{P}$, foi muito maior, correspondendo a frações relativamente grandes da dose aplicada, como é comum na aplicação de P ao solo (Murthy \& Kotur, 1998).

Uma das conseqüências da livre translocação de P entre plantas mães e filhas é a extrapolação que poderia ser feita quanto à possibilidade da utilização de produtos químicos no desbaste da bananeira 'Pacovan'. Considerando que os produtos químicos tenham comportamento semelhante ao ${ }^{32} \mathrm{P}$, a aplicação desses produtos na eliminação da brotação indesejada poderia levar ao surgimento de toxicidade na planta-mãe. É necessário, porém, que pesquisas sobre desbaste químico sejam feitas, para determinar a dose adequada para que efeitos da toxicidade, para a planta-mãe, não interfiram economicamente na produtividade da cultura.

\section{CONCLUSÕES}

1. Houve ininterrupta translocação de fósforo entre plantas mãe e filha e vice-versa aos 2, 4 e 6 meses de idade da planta-filha.

2. A translocação do fósforo foi sempre mais intensa no sentido planta-filha para planta-mãe, notadamente aos dois meses de idade da planta-filha.

3. As plantas mãe e filha podem, além de utilizar suas raízes para absorção de nutrientes, beneficiar-se dos nutrientes absorvidos pelo sistema radicular da outra.

\section{REFERÊNCIAS}

BALAKRISHNAN, R.; SHANMUGAVELU, K.G. Translocation of ${ }^{32} \mathrm{P}$ between mother and sucker at different stages in banana cultivars of different ploidy levels. Banana Newsletter, Brisbane, n.8, p.2830, 1985.

BAPAT, V.A.; NIRALE, A.S.; KULKARNI, V.M.; SUPRASANNA, P.; RAO, P.S. Studies on mineral uptake using tissue culture derived plants of banana (Musa sp.). Journal of Plant Biochemistry and Biotechnology, New Delhi, v.10, p.76-81, 2001.

BEUGNON, M.; CHAMPION, J. Étude sur les racines du bananier. Fruits, Paris, v.21, p.309-327, 1966.

BURAGOHAIN, R.; SHNMUGAVELU, K.G. A study on the translocation of plant nutrient from the sink towards the source in certain banana cultivars using ${ }^{32}$ P. Banana Newsletter, Brisbane, n. 8, p.31-33, 1985.

BURAGOHAIN, R.; SHNMUGAVELU, K.G. Studies on the nutrient content and uptake of the 'Vayal Vazhai' banana (ABB). Banana Newsletter, Brisbane, n.9, p.19-23, 1986.

EMBRAPA. Manual de análises químicas de solos, plantas e fertilizantes. Brasília: Embrapa Informática Agropecuária, 1999. 370p.
FONTES, P.S.F.; CARVALHO, A.J.C.; CEREJA, B.S.; MARINHO, C.S.; MONNERAT, P.H. Avaliação do estado nutricional e do desenvolvimento da bananeira-prata-anã (Musa spp.) em função da adubação nitrogenada. Revista Brasileira de Fruticultura, Jaboticabal, v.25, p.156-159, 2003.

KURIEN, S.; ANIL, B.K.; RAJEEVAN, P.K.; BHARATHAN, V.; KRISHNAN, S. Phosphorus mobilization to uneconomic tissues and effects of bunch trimming regimes in banana. Sciencia Horticulturae, Amsterdam, v.83, p.25-32, 2000.

LOPEZ, M.A.; ESPINOSA, M.J. Manual de nutrición y fertilización del banano. Quito: Instituto de la Potassa y el Fósforo, 1995. 82p.

LÓPEZ, A.; ESPINOSA, J. Banana response to potassium. Better Crops International, Athens, v.12, p.3-5, 1998.

MAIA, V.M.; SALOMÃO, L.C.C.; CANTARUTTI, R.B. ; VENEGAS, V.H.A. ; COUTO, F.A.A. Efeitos de doses de nitrogênio, fósforo e potássio sobre os componentes da produção e a qualidade de bananas-'prata-anã' no distrito industrial de Jaíba. Revista Brasileira de Fruticultura, Jaboticabal, v.25, p.319-322, 2003.

MARCHAL, J.; MALLESSARD, R. Comparaison des imobilisations minérales de quatre cultivars de bananiers à fruits pour cuisson et de deux 'Cavendish'. Fruits, Paris, v.34, n.6, p.373-392, 1979.

MARTIN-PRÉVEL, P. Echantillonnage du bananier pour l'analyse foliaire; conséquences des différences de techniques. Fruits, Paris, v.32, n.3, p.151-166, 1977.

MURTHY, S.V.K.; KOTUR, S.C. Effect of time and placement method of ammonium sulphate and superphosphate on the comparative efficiency of $\mathrm{N}$ and $\mathrm{P}$ absorption and utilization in 'Robusta' banana (Musa x paradisiaca) using labelled fertilizers. Indian Journal of Agricultural Sciences, New Delhi, v.68, p.765-768, 1998.

NOVAIS, R.F.; SMYTH, T.J. Fósforo em solo planta em condições tropicais. Viçosa: Universidade Federal de Viçosa, 1999. 399p.

PEREIRA, M.C.T.; SALOMÃO, L.C.C.; SILVA, S.O.; SEDIYAMA, C.S.; COUTO, F.A.A.; SILVA NETO, S.P. Crescimento e produção de primeiro ciclo da bananeira 'prata-anã' (AAB) em sete espaçamentos. Pesquisa Agropecuária Brasileira, Brasília, v.35, p.1.377-1.387, 2000.

RAGHUPHATI, H.B.; REDDY, B.M.C.; SRINIVAS, K. Multivariate diagnosis of nutrient imbalance in banana. Communications in Soil Science and Plant Analysis, New York, v.33, p.2.131-2.143, 2002.

SIDRA / IBGE. Produção agrícola municipal. Disponível em: $<$ www.sidra.ibge.gov.br>. Acesso em: 5 abril 2005.

STATSOFT. Statistica for Windows, version 5.0. Copyright Statsoft. 1995.

TWYFORD, I.T. Banana nutrition, a review of principles and practice. Journal of the Science Food and Agriculture, London, v.18, p.177183,1967

TWYFORD, I.T.; WALMSLEY, D. The mineral composition of the Robusta banana plant. I. Methods and plant growth studies. Plant and Soil, Dordrecht, v.39, p.227-243, 1973.

VEERANNAH, L.; SELVARAJ, P.; ALAGIAMANAVALAN, R.S. Studies on the nutrient uptake in Robusta and Poovan. Indian Journal of Horticulture, Bangalore, v.33, p.203-208, 1976.

WALMSLEY, D.; TWYFORD, I.T. The translocation of phosphorus within a stool of Robusta bananas. Tropical Agriculture, St. Augustine, v.45, n.3, p.229-233, 1968a.

WALMSLEY, D.; TWYFORD, I.T. The uptake of ${ }^{32} \mathrm{P}$ by the Robusta banana. Tropical Agriculture, St. Augustine, v.45, n.3, p.223-228, $1968 \mathrm{~b}$.

WALMSLEY, D.; TWYFORD, I.T. The zone of nutrient uptake by the Robusta banana. Tropical Agriculture, St. Augustine, v.45, n.2, p.113-118, 1968c. 